Sharif University of Technology
Scientia Iranica
SCIENTIA
I RAN I CA
Transactions A: Civil Engineering
www.scientiairanica.com

\title{
Optimal TMDs for improving the seismic performance of historical buildings
}

\author{
M. Mohebbi ${ }^{a, *}$ and A. Joghataie ${ }^{b}$ \\ a. Department of Engineering, University of Mohaghegh Ardabili, Ardabil, P.O. Box 56199-11367, Iran. \\ b. Department of Civil Engineering, Sharif University of Technology, Tehran, P.O. Box 11155-9313, Iran. \\ Received 30 June 2014; received in revised form 25 February 2015; accepted 4 May 2015
}

\author{
KEYWORDS \\ Tuned Mass Damper \\ (TMD); \\ Optimization; \\ Genetic Algorithm \\ (GA); \\ Confined masonry \\ walls; \\ Seismic response.
}

\begin{abstract}
In this paper, optimal design and assessment of the capability of Tuned Mass Dampers (TMDs) in improving the seismic behavior of confined masonry walls, as the main element of historical buildings, has been studied. For this purpose, the design parameters of TMDs have been determined through minimization of wall response using Genetic Algorithms (GAs). To simulate the behavior of confined masonry wall under earthquake, the triple linear shear beam model has been used. For illustration, the method has been tested on confined masonry walls equipped with linear TMDs. To study the effects of frequency content and Peak Ground Acceleration (PGA) of earthquake records on the performance of TMDs, the controlled walls have been subjected to different earthquake records. Results show that the proposed method has been effective in designing optimal TMDs regarding the convergence and simplicity of GA in solving the optimization problem. It has also been shown that using TMD enhances the seismic behavior of confined masonry walls, which its efficiency depends on the earthquake characteristics and the mass ratio. Finally, it can be concluded that the results of this research could be used as guides to design TMDs for historical and heritage buildings.
\end{abstract}

(C) 2016 Sharif University of Technology. All rights reserved.

\section{Introduction}

Most of the masonry structures around the world are considered as historical buildings or national heritage and need to be protected against environmental loads. The behavior of these structures is highly nonlinear and hysteretic and different models have been proposed to simulate their dynamic behavior. In addition to that of Moghaddam and Dowling [1] who have extensively studied the behavior of infilled frames, different models have been proposed to predict the dynamic response of masonry infilled frames, such as the truss model [2] or the analytical macro-model based on an equivalent

\footnotetext{
*. Corresponding author. Tel.: +98-4533512910; Fax: +98-4533512904

E-mail addresses: mohebbi@uma.ac.ir (M. Mohebbi); joghatae@sharif.edu (A. Joghataie)
}

strut approach [3]. Tomazevic and Klemenc [4-5] have proposed a tri-linear model of lateral resistancedisplacement envelope curve for representing the seismic behavior of confined masonry walls, where the resistance is calculated as a combination of the shear resistance of the plain masonry wall panel and the dowel effect of the tie-column's reinforcement. A trilinear shear spring model has also been proposed by Moroni et al. [6,7] for the dynamic behavior of confined masonry walls and their nonlinear properties.

Since masonry buildings are highly vulnerable to earthquake ground shakings, their protection against earthquake excitation is absolutely necessary. One alternative to protect such buildings is using structural control systems. Joghataie and Mohebbi [8] have worked on this subject by studying the effect of application of active control systems on confined masonry walls. They have concluded that active 
controlling of confined masonry walls could be effective for keeping the masonry walls from failure under severe earthquakes. As some advantages of passive control systems, such as their simplicity and availability of the required technologies, have made passive control more attractive and practical, in this paper, it has been decided to assess if passive control strategies could be effectively applied to mitigate the seismic response of confined masonry walls.

In the area of passive control, much progress has been accomplished, especially in base isolation and different types of mechanical energy dissipaters, such as single Tuned Mass Damper (TMD) [9], double TMD [10], and multiple TMD [11-14]. The optimization of TMD parameters has been studied in structural control for many years and different methods have been proposed for optimal design of TMDs for linear structures, including selecting the parameters of a TMD for the undamped structure under sinusoidal excitation [15], minimization of the Root-Mean-Square (RMS) of the main structure's displacement or acceleration under white noise excitation [16], maximization of the effective damping of the structure incorporating the TMD [17], and minimization of the difference between the damping values of the first two modes of the structure-TMD coupled system [18]. Also, in recent research, new types of TMDs have been investigated for attenuating oscillations of structures, such as magnetically tuned mass dampers proposed for vibration control of large structures [19], the Bidirectional TMD (BTMD) for vibration control of irregular high rise building [20], and Tuned Mass Damper-Inerter (TMDI) which generalizes the classical Tuned Mass Damper (TMD) to reduce the oscillatory motion of stochastically support excited structural systems [21]. Since in real underground shaking many buildings undergo large deformations, the application of TMD to nonlinear structures has also been studied in some research. The seismic effectiveness of TMDs for elastic-perfectly plastic single degree of freedom under earthquake motions [22], the effect of ground motion on effectiveness of TMDs on nonlinear structures [23], and the use of accumulated hysteretic energy absorption in conjunction with the maximum displacement of nonlinear structures to assess the effectiveness of TMD [24] have been investigated in previous research. Also, using Nonlinear Rooftop Tuned Mass Damper Frames (NRTMDF) to retrofit structures [25] and Nonlinear Tuned Mass Damper (NTMD) and an adaptive-length pendulum tuned mass damper (APTMD) to reduce the response of hardening Düffing oscillator have been suggested [26]. Mohebbi and Joghataie [27] studied the effectiveness of TMD on Multi-Degree Of Freedom (MDOF) frames with nonlinear and hysteretic behavior and proposed a method to determine the optimal values of TMD parameters based on minimizing a specified objective function. In this paper, the effectiveness of TMDs in mitigating the seismic response of nonlinear and hysteretic confined masonry walls has been studied. For this purpose, following the method proposed by Mohebbi and Joghataie [27], an optimization procedure based on using Genetic Algorithm (GA) has been applied to design optimal TMDs for controlling the response of confined masonry walls with different numbers of storeys equipped with linear TMDs under different earthquakes. Moreover, the effects of input ground motion, TMD mass ratio and different design criteria on the performance of TMDs have been discussed.

In the following sections, firstly Moroni's model [6] for confined masonry walls and then the formulation of optimization problem for the design of optimal TMDs will be briefly reviewed. A brief explanation of the GA will be presented followed by numerical examples and conclusions.

\section{Moroni's model for confined masonry walls}

For modeling the dynamic behavior of confined masonry walls, different models have been proposed in literature [3-6]. Among the proposed models, the one proposed by Moroni et al. [6] has been based on extensive experimental results on real scale confined masonry walls. Therefore, using this model for numerical simulations leads to achieve a close similarity with the results of existing masonry walls and thus a more accurate analysis. Also, this model includes parameters which enable modeling of masonry wall in different conditions without any complexity in numerical simulations. Hence, in this paper, it has been decided to use this model for representing the nonlinear behavior of confined masonry walls under earthquake excitation. The model has been based on a tri-linear shear spring model with hysteresis loops, as shown in Figure 1, wherein the horizontal and vertical axes represent the shear strain, $\gamma$, and lateral force, $V$, respectively. The parameters of this model, shown in Figure 1, are:

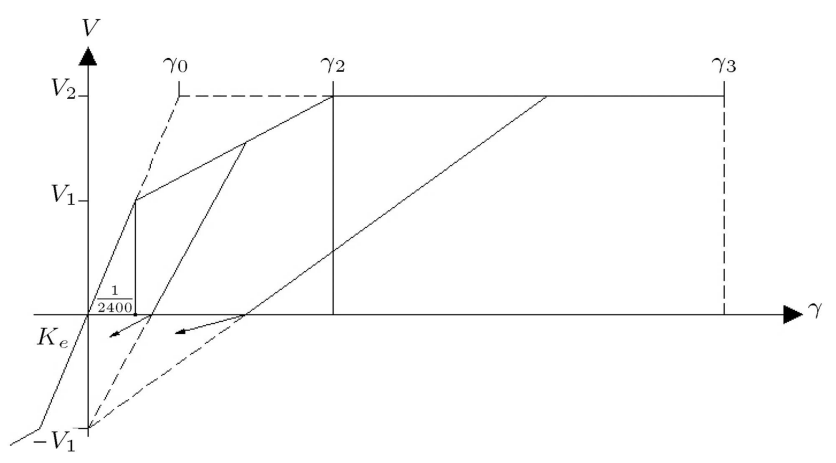

Figure 1. Triple linear shear beam model [8]. 
$V_{1}$

The initial yield point after which the wall becomes nonlinear corresponding to shear strain $\gamma=1 / 2400$;

$V_{2} \quad$ Plastic shear capacity;

$K_{e} \quad$ Effective initial stiffness of the shear spring;

$\gamma_{0}$

Elasto-plastic strain corresponding to the stiffness, $K_{e}$, and lateral load, $V_{2}$; The real strain corresponding to the lateral load, $V_{2}$;

The strain at which the wall fails, where the failure displacement is calculated as:

$$
X_{\text {failure }}=h \gamma_{3} \text {, }
$$

where $h$ is the wall height.

The above parameters can be calculated according to the following formulae:

$$
\begin{aligned}
& V_{1}=\left(0.19 \tau_{m}+0.12 \sigma_{0}\right) A m \\
& V_{2}=\left(0.37 \tau_{m}+0.43 \sigma_{0}\right) A m \\
& \gamma_{2}=\alpha_{1} \gamma_{0} \\
& \gamma_{3}=\alpha_{2} \gamma_{0} \\
& \gamma_{0}=\left(V_{2} / k_{e}\right) / h \\
& A_{e}=A m+2\left(G_{c} / G_{m}\right) A_{c}
\end{aligned}
$$

For artisan brick and hollow concrete blocks, the effective initial stiffness, $K_{e}$, is determined as:

$$
\begin{aligned}
& k_{e}=G_{m} \frac{A_{e}}{3}, \\
& k_{e}=G_{m} \frac{A_{e}}{6},
\end{aligned}
$$

where $\sigma_{0}$ is the applied vertical load on the wall, $\tau_{m}$ is the shear strength of the wall, $A_{m}$ is the area of the masonry wall cross section, $A_{c}$ is the total area of the exterior confining columns, $G_{m}$ and $G_{c}$ are shear modulus of the masonry and concrete materials, respectively, and $\alpha_{1}$ and $\alpha_{2}$ are two constants which are experimentally determined.

The model in Figure 1 assumes that after the initial yielding point, when the base shear is positive, unloading follows a straight line which connects the current point on Figure 1 to point $\left(0,-V_{1}\right)$ on the vertical axis; then, the line breaks at its intersection point with the horizontal axis and points towards the previous extremum point of the negative base shear. The same rules are valid for negative base shear too, where the reloading from negative towards positive shear follows a broken line characterized by point $\left(0,+V_{1}\right)$ and the previous extremum point of the positive base shear.

\section{Designing optimal TMDs}

Most of the proposed methods [15-18] have been developed for designing TMDs for linear structures, where tuning the TMD parameters could be performed based on the constant properties of the structure. However, for structures, such as confined masonry walls, which exhibit highly inelastic behavior under moderate and severe earthquakes, the stiffness and consequently the frequency of the structure change during the excitation. Hence, it causes the TMD, designed by assuming constant frequency for the structure, to be detuned and thus decrease in efficiency. Therefore, in this paper, designing optimal TMDs has not been directly based on the frequency tuning, which is commonly used for linear systems.

Instead, in this paper, following the method proposed by Mohebbi and Joghataie [27] for optimal design of TMDs on nonlinear frames, optimal values of TMD parameters are determined based on minimizing the maximum value of any desired objective function, $V(t)$, such as relative displacement (drift), root-meansquare of response, or accumulated hysteretic energy, which can be considered as a function of the structural response under the design earthquake excitation.

Defining $\Delta t=$ sampling time interval, the problem can be stated to find the constrained minimum of the maxima as follows:

$$
\begin{aligned}
& \text { Find } Q=\left(m_{d}, c_{d}, k_{d}\right) \\
& \text { Minmax } V(t)_{k}, \quad k=1,2, \ldots, k_{\max }
\end{aligned}
$$

subject to:

$$
\begin{aligned}
& F=\text { equality constraints on TMD-structure } \\
& \text { response, } \\
& G=\text { inequality constraints on TMD-structure } \\
& \text { response, }
\end{aligned}
$$

where $Q$ represents the vector of the TMD parameters $m_{d}, c_{d}$, and $k_{d}$, which are the mass, damping, and stiffness of the TMD and $k_{\max }$ is the total number of analysis time steps.

The parameters of TMD in the optimization problem defined in Eqs. (10a) to (10d) can be determined in such a way that some constraints or criteria on the response or parameters of TMD are satisfied.

\section{Genetic algorithm}

Genetic algorithms, developed by Holland [28], have proven to be successful direct searching algorithms for solving nonlinear optimization problems, where 
the derivatives of the objective function and/or constraints of the problem are not available or are hard to compute. In an optimization problem, a design vector can be considered as a chromosome, its design components as its genes, and its corresponding value of the objective function as a measure of the chromosome fitness. In GAs, chromosomes evolving under a certain environment are represented by bit strings or real-valued coding. In the early stages of string coding, the variables were represented in a binary format $[29,30]$. Whilst binary-coded GAs appear to be more suitable when solving complex problems, they have some drawbacks in taking continuous problems and it has been shown that for real-valued numerical optimization problems, real-valued coding representations offer certain advantages [31,32]. In this paper, the real-valued coding has been used for presenting the chromosomes. GA starts with a discrete set of design vectors and changes the current set towards generating a fitter generation of design points through three genetic algorithm operators including selection, crossover, and mutation. In every generation, a set of chromosomes is selected for mating based on their relative fitness. The fitters are given more chance of passing their genes into the next generation. In this paper, the stochastic universal sampling method [33] has been used for selecting a number of chromosomes for mating, based on their fitness values in the current population, as:

$$
P\left(x_{i}\right)=\frac{F\left(x_{i}\right)}{\sum_{i=1}^{N_{\text {ind }}} F\left(x_{i}\right)}, \quad i=1,2, \ldots, N_{i n d},
$$

where $F\left(x_{i}\right)$ is the fitness of chromosome, $x_{i}$, and $P\left(x_{i}\right)$ is the probability of selection of $x_{i}$, also $N_{i n d}$ is the number of individuals.

Crossover produces new individuals. In this paper, the method proposed by Mühlenbein and Schlierkamp-Voosen [34] has been used for crossover, where each pair of parents can produce two newborns and each newborn can get its genes from its parents with equal probability as follows:

$$
O=P_{1}+\alpha\left(P_{2}-P_{1}\right),
$$

where $P_{1}$ and $P_{2}$ are the parent chromosomes' genes, $O$ is the newborn gene, and $\alpha$ is a scaling factor chosen randomly over $[-0.25,1.25]$ interval, typically. This method uses a new $\alpha$ for each pair of parent genes. Mutation, which helps the GA escape from local minima, is performed at a specified low rate in certain chromosomes.

The elitist strategy, which allows the best chromosomes of the current generation to go to the next generation without modification, has been used in this research. $N_{\text {elites }}$ of the best chromosomes are selected as elites of the current generation to go to the next generation without modification. The rest of the chromosomes in the population are replaced by the inserted newborns $\left(N_{\text {ins }}\right)$. Hence:

$$
N_{\text {elites }}=N_{\text {ind }}-N_{\text {ins }} \text {. }
$$

To make GA more effective in solving optimization problems, improved versions of GA, such as parallel genetic/neural network learning algorithm [35], bilevel GA [36], and distributed GAs [37], have been developed. Also, combination of GA with fuzzy logic and neural network has shown better performance in solving optimization problem [38-42].

GA has been used for solving the optimization in different fields of civil engineering, such as structure optimization [43-46], space frames design [47], system identification [48], and transportation $[49,50]$. Also in designing structural control systems as instance, neurogenetic algorithm has been used for designing optimal nonlinear active controller for high rise buildings [39], designing optimal active controllers for nonlinear structures [51,52], multiple TMDs [12,13], and MR dampers for structures [53], and optimization of earthquake energy dissipation system for high rise buildings [54]. GA has been applied extensively. Results of research have proven the effectiveness of GA in solving linear and nonlinear optimization problems, even in the cases with a large number of variables. In this research, the optimization problem includes two variables, since for nonlinear optimization problem, using traditional gradient-based optimization techniques need massive numerical analysis; hence, GA has been used for the optimization.

\section{Numerical examples}

\subsection{Example 1}

In this paper, the main objective has been to assess the effectiveness of optimal TMDs in mitigating the response of confined masonry buildings subjected to earthquakes. Since the related research is limited, and also to focus on the main problem and avoid complexity at this stage of research, we decided to perform the analysis on $2 \mathrm{D}$ masonry walls. Since $2 \mathrm{D}$ masonry walls are the main element of 3D masonry buildings, the result and the design procedure of this paper could be easily extended to real 3D confined masonry buildings in future research. The confined masonry wall, shown in Figure 2, has been modeled according to Moroni et al. [6] and the mitigation of its vibrations by a single TMD has been investigated. The dimensions of the wall are $240 \mathrm{~cm} \times 240 \mathrm{~cm} \times 15 \mathrm{~cm}$, and there is a uniformly distributed mass of $p_{0}=66 \mathrm{~N} . \mathrm{s}^{2} /(\mathrm{m} . \mathrm{cm})$ on top of the wall. The initial and secondary shear stiffness values of the wall are $432621 \mathrm{~N} / \mathrm{cm}$ and $49544 \mathrm{~N} / \mathrm{cm}$, respectively, and the elastic and plastic 


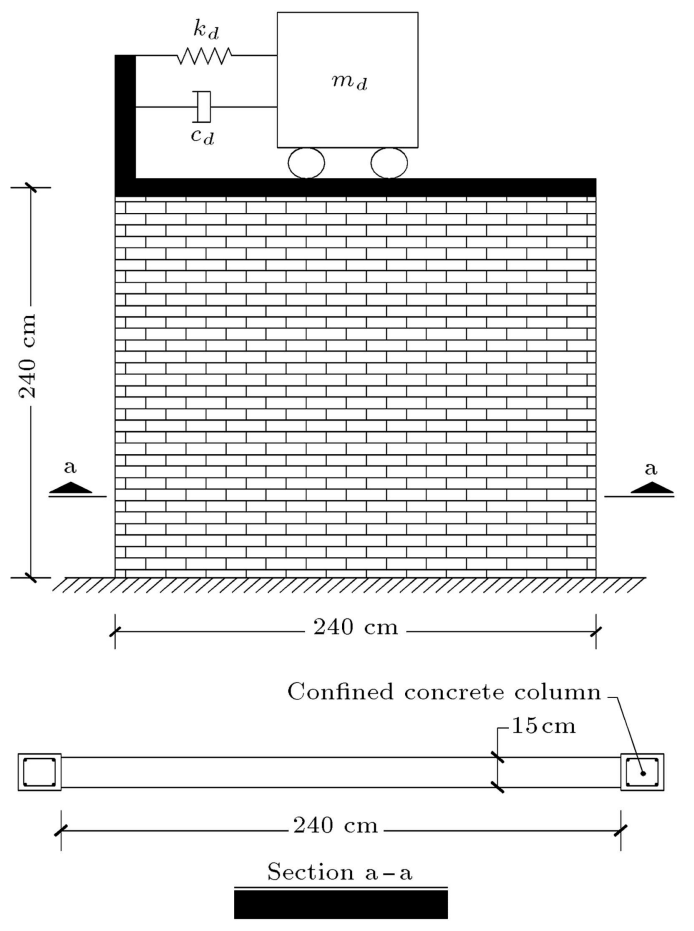

Figure 2. Masonry wall-TMD model.

shear strengths are $V_{1}=34415 \mathrm{~N}$ and $V_{2}=97525 \mathrm{~N}$, respectively. The damping of the wall is $826.34 \mathrm{~N} . \mathrm{s} / \mathrm{cm}$ which corresponds to $5 \%$ damping ratio as suggested by Moroni et al. [7]. From Eqs. (1), (4), and (5), the nonlinear behavior begins at $X_{n l}=0.08 \mathrm{~cm}$ and the failure occurs when the displacement exceeds $X_{\text {failure }}=4.28 \mathrm{~cm}$. Also, according to Eq. (4), after the displacement exceeds $X_{\text {yielding }}=1.35 \mathrm{~cm}$, it increases without significant increase in the lateral load.

\subsubsection{TMD design earthquake}

To assess the effect of frequency content and the Peak Ground Acceleration (PGA) of earthquake on efficiency of TMD, earthquakes of different magnitudes, including a white noise, $W(t)$, with PGA $=100 \mathrm{~cm} / \mathrm{s}^{2}(\approx 0.1 \mathrm{~g})$ as shown in Figure 3, the El Centro (1940, PGA $=0.34$ $\mathrm{g})$, and the Tabas $(1978, \mathrm{PGA}=0.933 \mathrm{~g}$ ) earthquakes, have been first scaled and then used for designing

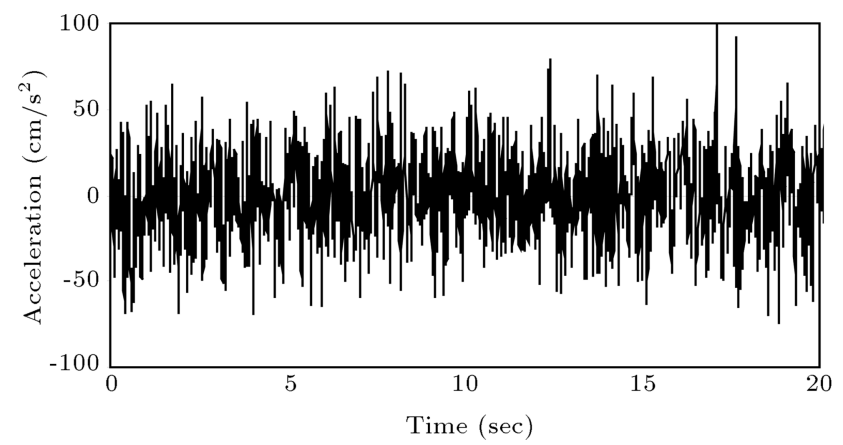

Figure 3. White noise ground acceleration, $W(t)$, with $\mathrm{PGA}=100 \mathrm{~cm} / \mathrm{s}^{2}$.
Table 1. Maximum response of uncontrolled wall under different scaled earthquakes.

\begin{tabular}{ccccc}
\hline $\begin{array}{c}\text { Scaled } \\
\text { earthquake }\end{array}$ & $\begin{array}{c}\text { Drift } \\
(\mathbf{c m})\end{array}$ & $\begin{array}{c}\text { Acc. } \\
\left(\mathbf{c m} / \mathbf{s}^{2}\right)\end{array}$ & $\begin{array}{c}\text { AHE } \\
(\mathbf{N . m})\end{array}$ & $\begin{array}{c}\text { Drift } \\
\text { RMS } \\
(\mathbf{c m})\end{array}$ \\
\hline $17.5 \times W(t)$ & 4.28 & 1713 & 50643 & 1.24 \\
$1.5 \times$ El Centro & 1.37 & 943 & 5016 & 0.19 \\
$2.55 \times$ El Centro & 4.28 & 1231 & 18579 & 0.72 \\
$2.84 \times$ El Centro & 6.4 & 1365 & 23238 & 0.94 \\
$1.137 \times$ Tabas & 4.28 & 1624 & 13091 & 0.96 \\
\hline
\end{tabular}

TMDs. The PGA of a scaled earthquake, $\mathrm{PGA}_{\max }$, has been defined as:

$$
\mathrm{PGA}_{\max }=\lambda \cdot \mathrm{PGA},
$$

where $\lambda$ is the scale factor. For different values of $\lambda$, the masonry wall has been analyzed under scaled design earthquakes and the values of $\lambda$, for which the wall has experienced yielding and failure displacement, have been determined. It has been found that for $\lambda \geq 17.5$, 2.55 , and 1.137 , the maximum relative displacement (drift) of the masonry wall has exceeded the failure displacement, $X_{\text {failure }}=4.28 \mathrm{~cm}$, under the $W(t)$, the El Centro, and the Tabas earthquakes, respectively. Also, for $\lambda \geq 2.84$, under the El Centro excitation, the maximum displacement has been $X_{\max }=6.4 \mathrm{~cm}$, which is $200 \%$ of failure displacement.

The maximum response of uncontrolled masonry wall under the different scaled design earthquakes has been shown in Table 1, where the maximum RootMean-Square (RMS) of drift as well as Accumulated Hysteretic Energy (AHE) of an $n$ storey wall can be calculated according to the following equations:

$$
\begin{aligned}
& \operatorname{RMS}(y(i))=\left(\frac{\sum_{k=1}^{k_{\max }} y(i)_{k}^{2}}{k_{\max }}\right)^{1 / 2}, \quad i=1,2, \ldots, n, \\
& \operatorname{RMS}_{\text {max }}(y)=\max |\operatorname{RMS}(y(i))|, \quad i=1,2, \ldots, n,
\end{aligned}
$$

where $y(i)$ is relative displacement (drift) of $i$ th storey. Also, for a nonlinear structure with hysteresis loops, AHE of each storey is defined as:

$$
\begin{gathered}
\operatorname{AHE}(i+1, j)=\operatorname{AHE}(i, j)+\frac{f_{s}(i)+f_{s}(i+1)}{2} \\
{\left[y_{i+1}(j)-y_{i}(j)\right],} \\
i=1,2, \ldots, k_{\max } \text { and } j=1,2, \ldots, n,
\end{gathered}
$$

where $\operatorname{AHE}(i, j), f_{s}(i)$, and $y_{i}(j)$ are accumulated hysteretic energy, shear force, and relative displacement (drift) at time $i \Delta t$ of the storey $j$. 


\subsubsection{Effect of earthquake frequency content on the performance of $T M D$}

For assessing the effect of earthquake frequency content on the performance of TMDs, the $W(t)$, the El Centro, and the Tabas earthquakes have been scaled with scale factors $\lambda=17.5,2.55$, and 1.137 , respectively, and then used to design optimal TMDs, where the maximum displacement of uncontrolled masonry wall under theses scaled records has been $X_{\max }=X_{\text {failure }}=$ $4.28 \mathrm{~cm}$.

\subsubsection{Finding TMD parameters based on minimizing the maximum drift}

For nonlinear structures, especially for confined masonry walls where the nonlinear behavior begins at low level of displacement, the stiffness and, as the result, the frequency of structures varies during the excitation. Hence, unlike designing TMDs for linear structures where the parameters of TMD are usually determined based on tuning TMD frequency to that of the structure, in nonlinear structures as soon as the structure experiences nonlinearity, detuning occurs. For this reason, designing optimal TMDs has not been directly according to frequency tuning in this paper. Alternatively, as previously mentioned, optimal values of TMD parameters are determined based on solving an optimization problem which includes minimization of a specified objective function. The most commonly used criterion to measure the effectiveness of a TMD on a structure is the amount of reduction in the maximum relative displacement (drift) of the structure. Hence, in the first section, the optimization problem herein is defined so as to minimize the maximum relative displacement, $X_{\max }$, of the wall as the objective function while being subjected to some constraints on the TMD response and its parameters. For a specified value of TMD mass ratio, $\mu=m_{d} / m_{\text {tot }}$, where $m_{\text {tot }}$ denotes the total mass of the structure, the optimization problem for a one-storey wall can then be defined as:

$$
\begin{aligned}
& \text { Find } Q\left(c_{d}, k_{d}\right) \text {, } \\
& \text { Minimize } X_{\max }=\max \left(\left|X_{k}\right|, k=1,2, \ldots, k_{\max }\right) .
\end{aligned}
$$

Subject to:

$$
\begin{aligned}
& X_{\max }(\mathrm{TMD}) \leq X_{L}, \\
& 0<c_{d}<c_{d \max }, \quad 0<k_{d}<k_{d \max },
\end{aligned}
$$

where $X_{L}$ is the maximum stroke length of TMD, $X_{\max }(\mathrm{TMD})$ is the maximum displacement of TMD, and $c_{d \max }$ and $k_{d \max }$ represent the maximum possible stiffness and damping of TMD, which should be considered by the designer.

To solve the optimization problem defined in Eqs. (18a)-(18d), Genetic Algorithm (GA) has been used. To this end, first, the optimization problem has been changed to unconstraint problem by considering the constraints as penalty function as follows:

$$
\text { Find } Q\left(c_{d}, k_{d}\right) \text {, }
$$

$$
\begin{aligned}
& \text { Minimize } F(Q)=\alpha X_{\max }+\beta \max \left\lfloor 0, g_{1}\right\rfloor, \\
& g_{1}=\frac{X_{\max }(\mathrm{TMD})}{X_{L}}-1,
\end{aligned}
$$

where $\alpha$ and $\beta$ are penalty parameters which are specified through parametric study or by trial and error [8]. These parameters have no significant effect on the final answer while affect the convergence speed of the optimization problem. For this study, the values of $\alpha, \beta$, and $X_{L}$ have been selected as:

$$
\beta=100, \alpha=\frac{1}{X_{\max (\text { uncon. })}}=\frac{1}{4.28^{\mathrm{cm}}}, X_{L}=\underset{(20)}{50 \mathrm{~cm} .}
$$

For different values of the TMD mass ratio, the optimal parameters of TMDs have been determined by solving the optimization problem defined in Eqs. (19a)-(19c) using GA.

The following parameters have been selected for GA:

Number of individuals $=80$;

Number of elites $=8$;

Number of the newborns $=80$;

Insertion rate $=0.9$;

Mutation rate $=0.04$.

To solve the optimization problem for a given TMD mass ratio, an initial population consisted of 80 randomly generated vectors of TMD parameters, $Q=$ $\left(c_{d}, k_{d}\right)$, was generated. The maximum storey drift and the maximum TMD displacement were recorded. The objective function $F(Q)$ in Eq. (19b) was calculated for each $Q$. Iteratively, the population was modified following GA algorithm so that new generations were built until convergence was achieved. By monitoring the controlled response of the masonry wall corresponding to all the individual $Q_{s}$ in every generation, the fittest individual of that generation was identified. To guarantee the accuracy of the obtained optimum value of $Q=\left(c_{d}, k_{d}\right)$, different runs have been done in GA for each value of $\mu$.

For $\mu=5 \%$ under the scaled El Centro record, when $\lambda=2.55$, Figure 4 shows the best fitness value of the optimization problem through generations for different runs. Also, TMD stiffness and damping variations for four runs have been shown in Figure 5 where for the optimal TMD the optimum value of TMD parameters, maximum drift of the controlled masonry 


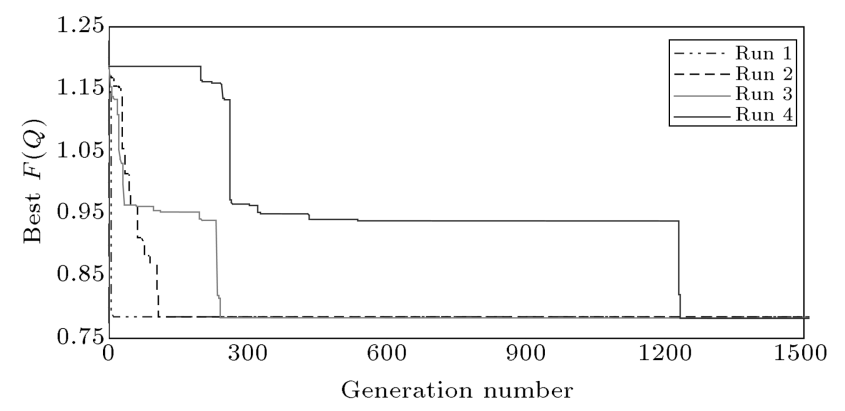

Figure 4. Convergence behavior of GA for four different runs.
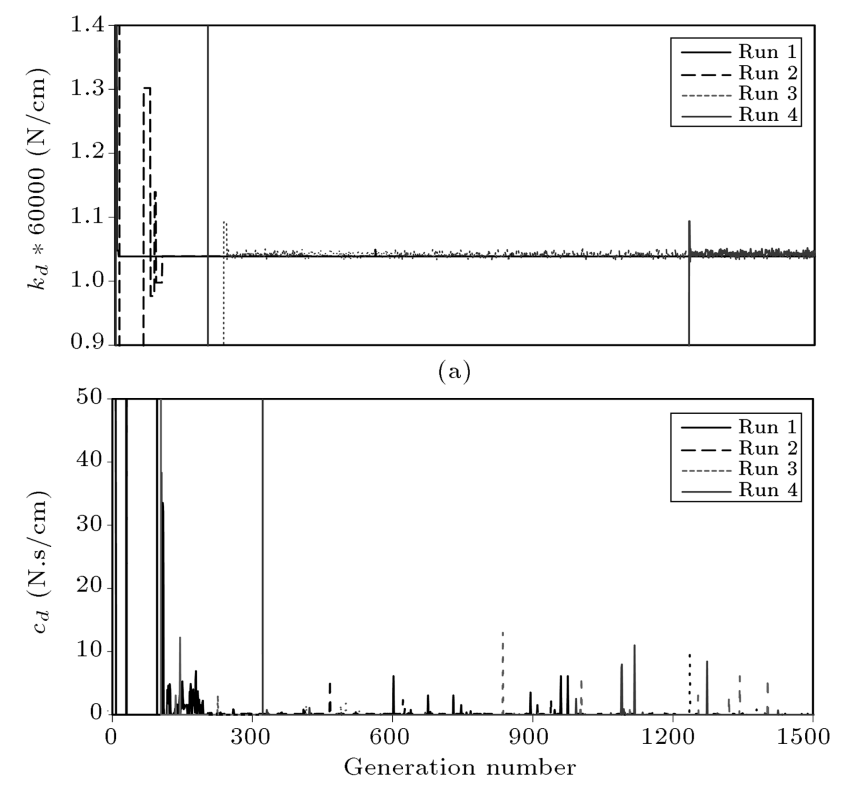

(b)

Figure 5. Variations of (a) TMD stiffness, and (b) TMD damping for four different runs.

wall, and TMD displacement have been as:

$$
\begin{aligned}
& Q=\left(c_{d}, k_{d}\right)=(0,62595 \mathrm{~N} / \mathrm{CM}), \\
& X_{\max }=3.35 \mathrm{~cm}, X_{\max }(\mathrm{tmd})=35 \mathrm{~cm} .
\end{aligned}
$$

Results show that all runs have approximately the same optimum answer including maximum drift, TMD stiffness, and damping, but with different convergence speeds. Hence, it can be concluded that the proposed method has been effective in designing optimal TMD for controlling the seismic response of confined masonry walls regarding the simplicity and convergence behaviour of the method.

The same procedure was followed for other values of $\mu$ and the optimal TMDs have been designed when the masonry wall was subjected to other scaled earthquake records. The maximum response of the structure obtained for different TMD mass ratios $(\mu=1.5 \%$ to $\mu=12.5 \%$ ) has first been normalized by dividing by the maximum uncontrolled values reported in Table 1 and then has been shown in Figure 6 .
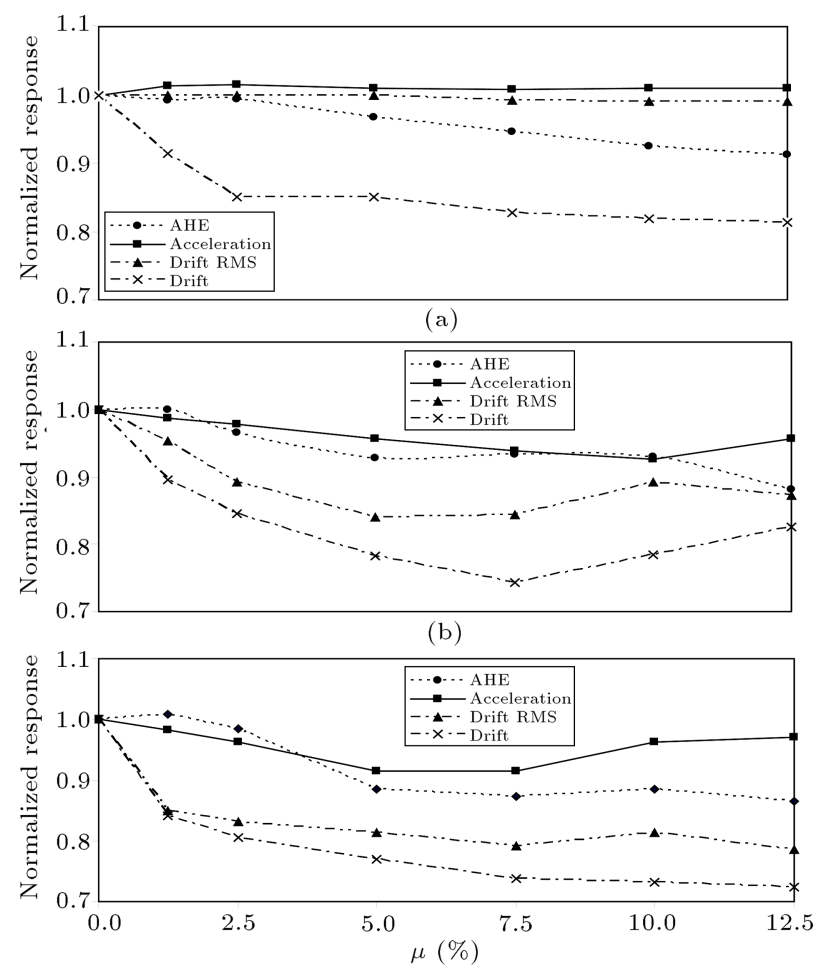

(c)

Figure 6. Normalized response of controlled wall versus TMD mass ratio for $($ a) $17.5 \times W(t)$, (b) $2.55 \times \mathrm{El}$ Centro, and (c) $1.137 \times$ Tabas.

According to results, it can be concluded that the performance of the designed TMDs in reducing the maximum response of the confined masonry wall and keeping the wall from failure depends on the earthquake frequency content where, for this case study, the maximum reduction in the maximum drift has been obtained under the scaled Tabas record. Also, the mass ratio of the TMD affects the efficiency of the TMD in reducing the maximum response where for most of the values of $\mu$, increasing the value of mass ratio leads to increase in the effectiveness of TMD.

From the results it can be concluded that since the earthquake frequency content affects the TMD performance, to design TMD for masonry walls in a particular area, it is needed to consider the historical earthquake database in that area and to determine the range of intensity of the earthquakes occurred in the past for the purpose of tuning the passive TMD accordingly.

\subsubsection{Effect of earthquake intensity on TMD performance}

To assess the effect of the intensity of an earthquake on the TMD performance, the masonry wall has been subjected to three different magnitudes of the El Centro earthquake with scale factors of $\lambda=1.5,2.55$, and 2.84. Referring to Table 1 , for the uncontrolled wall, the maximum drifts have been $X_{\max }=X_{\text {yielding }}=$ 


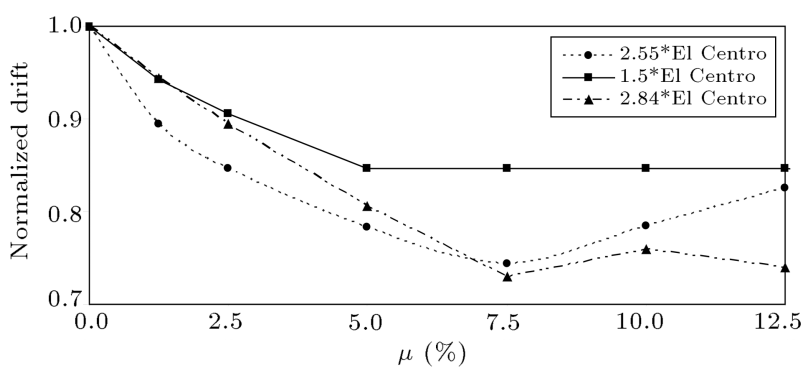

Figure 7. Normalized drift of controlled wall versus TMD mass ratio for different magnitudes of El Centro earthquake.

$1.35 \mathrm{~cm}, X_{\max }=X_{\text {failure }}=4.28 \mathrm{~cm}$, and $X_{\max }=$ $150 \% X_{\text {failure }}=6.41 \mathrm{~cm}$ for $\lambda=1.5,2.55$, and 2.84 , respectively. Figure 7 shows the normalized maximum drift of the controlled wall for the considered range of TMD mass ratios $\mu=1.5 \%$ to $\mu=12.5 \%$.

The results show that the effectiveness of TMD on masonry wall with nonlinear behavior strongly depends on the PGA of the design earthquake while for linear structures subjected to a specific excitation, the performance and optimum parameters of TMD are independent from excitation PGA. Therefore, it is noteworthy that in designing TMDs for masonry walls, in order to increase the efficiency of TMDs, the PGA of the design earthquake should be selected properly based on earthquake database.

\subsubsection{Designing optimal TMDs based on other criteria}

Another criterion which could be used when designing TMDs for nonlinear structures is minimization of the maximum root-mean-square of the relative displacement (drift) of the structure. Hence, in this paper, the optimal values of the TMD stiffness and its damping for a specified mass ratio have also been determined by solving the optimization problem defined as follows:

$$
\text { Find } Q\left(c_{d}, k_{d}\right) \text {, }
$$

$$
\text { Minimize } F(Q)=\gamma \operatorname{RMS}_{\max }(y)+\delta g_{1},
$$

where:

$$
g_{1}=\frac{X_{\max }(\mathrm{TMD})}{X_{L}}-1 .
$$

$\gamma$ and $\delta$ are penalty parameters and $X_{L}$ has been defined before.

Designing TMDs based on minimization of the maximum relative displacement of nonlinear structures has been the most commonly used index in the most works of research. Since this index cannot account for the effect of accumulation of damage that occurs in nonlinear structures under earthquake excitation, the Accumulated Hysteretic Energy (AHE), which is related to the cumulative damage, has also been

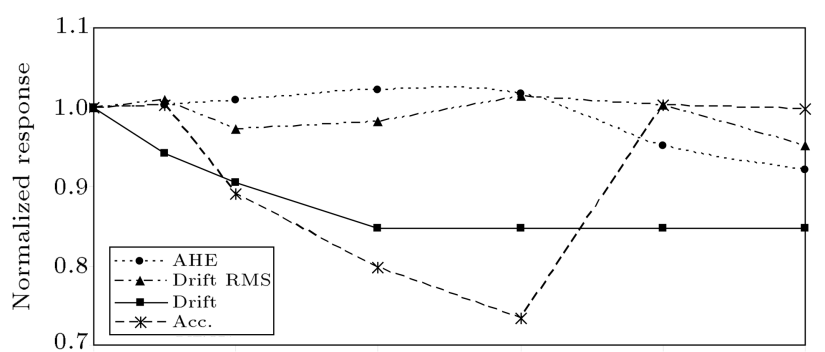

(a)
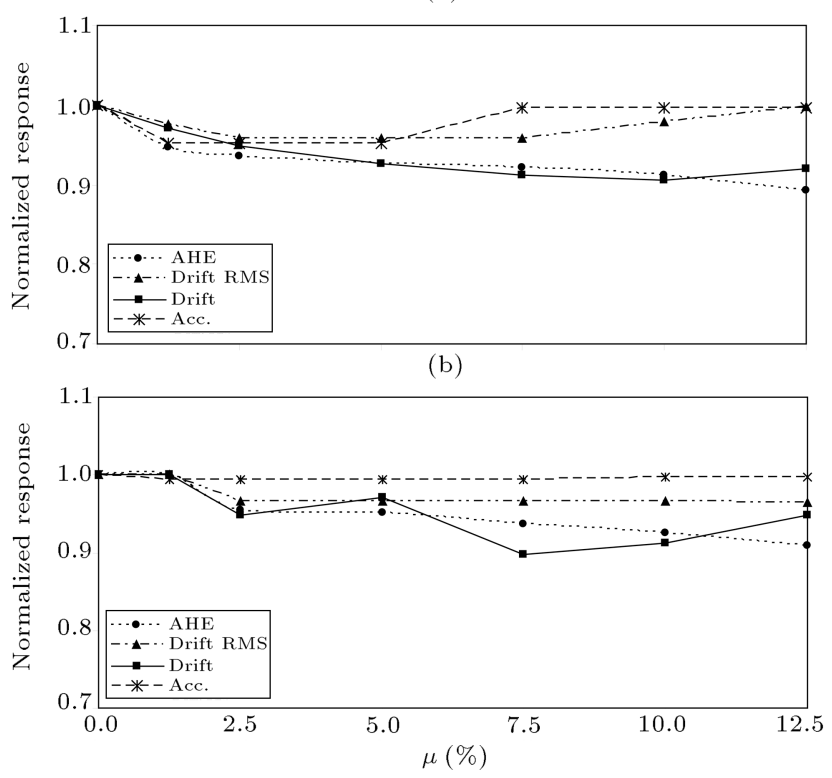

(c)

Figure 8. Normalized response of controlled wall when using (a) drift, (b) AHE, and (c) RMS of drift as design criterion in TMD designing procedure.

proposed to be used in assessing the performance of TMD on nonlinear structures [24,55].

In this paper, too, the minimization of the maximum accumulated hysteretic energy has been selected as another criterion for determining the optimal values of TMD parameters where the same procedure as that for drift and RMS of drift has been followed.

Figure 8 shows the normalized maximum drift, RMS of drift, AHE, and acceleration of the controlled masonry wall subjected to the scaled El Centro earthquake by $\lambda=1.5$ for the TMD mass ratios of $\mu=1.5 \%$ to $\mu=12.5 \%$ where TMDs have been designed based on minimizing the maximum drift, drift RMS, and Accumulated Hysteretic Energy (AHE). According to the results obtained from designing optimal TMDs based on different criteria, it can be said that, as expected, to achieve the maximum reduction in a specified response of masonry wall, it is needed to consider minimization of that particular response as the objective function. Also, the results show that there is no significant difference in the effectiveness of TMDs designed according to different performance indices in minimizing the maximum drift, RMS of drift, and 
AHE, which are safety indices of masonry walls, while for this case, the maximum reduction in the maximum acceleration has been achieved when the minimization of drift has been considered as the objective function. This mitigation of the acceleration can be important from the viewpoint of serviceability and convenience of the residents.

In designing TMDs, an important issue, which should be considered, is the instability of the structure equipped with TMD. The mass ratio in designing TMDs is usually a small value and does not generally cause instability in the structure. For the case study of this paper, the added mass has not caused any instability issues to the wall in the range considered for the mass ratio, i.e. $\mu=1.5 \%$ to $\mu=12.5 \%$. For a large value of mass ratio, however, it is possible to have instability in the structure and these values should not be used.

\subsection{Example 2}

As the second example to assess the effect of TMD in mitigating the seismic response of multi-storey confined masonry walls, a five-storey confined masonry wall equipped with a linear TMD on its top storey has been studied. Only as an example to illustrate the design procedure, the same property has been assumed for all stories of the wall, while in real masonry walls, the characteristics of each storey will be different. Since the same wall has been used for both examples, the failure displacement $X_{\text {failure }}=4.28$ has been the same for both walls. In this paper, the scale factor of the excitation has been selected, so that the maximum displacement has been $X_{\max }=X_{\text {failure }}=4.28 \mathrm{~cm}$. In Example 1, for the one-storey wall, another scale factor has been used to obtain the maximum displacement $X_{\max }=X_{\text {failure }}=4.28 \mathrm{~cm}$. It is worth mentioning that only to focus on the main issue of the paper and avoid complexity in numerical simulations, in this step of the research, the characteristics of the wall for each storey have been assumed to be the same as those for the confined masonry wall in Example 1. It is clear that using the same properties for all stories as those of one-storey masonry wall is only to simplify the modeling in numerical analysis; while, in real masonry walls, the characteristics of each storey will be different. The five-storey masonry wall has been modeled according to Moroni et al. [6].

To assess effectiveness of the proposed method, $W(t)$ excitation scaled by $\lambda=6.60$ has been used, where the maximum drift of the uncontrolled masonry wall has been shown in Table 2. The maximum drift of uncontrolled wall has been $X_{\max }=X_{\text {failure }}=$ $4.28 \mathrm{~cm}$ which shows the beginning of failure on the uncontrolled wall. To assess the capabilities of TMD in keeping the masonry wall from failure, it
Table 2. Maximum drift of uncontrolled wall under scaled white noise excitation.

\begin{tabular}{ccc}
\hline Storey & $\begin{array}{c}\text { Uncontrolled } \\
\text { wall drift } \mathbf{( c m )}\end{array}$ & $\begin{array}{c}\text { Controlled } \\
\text { wall drift }(\mathbf{c m})\end{array}$ \\
\hline 1 & 4.28 & 3.72 \\
2 & 2.28 & 2.15 \\
3 & 1.45 & 1.42 \\
4 & 1 & 0.89 \\
5 & 0.22 & 0.20 \\
\hline
\end{tabular}

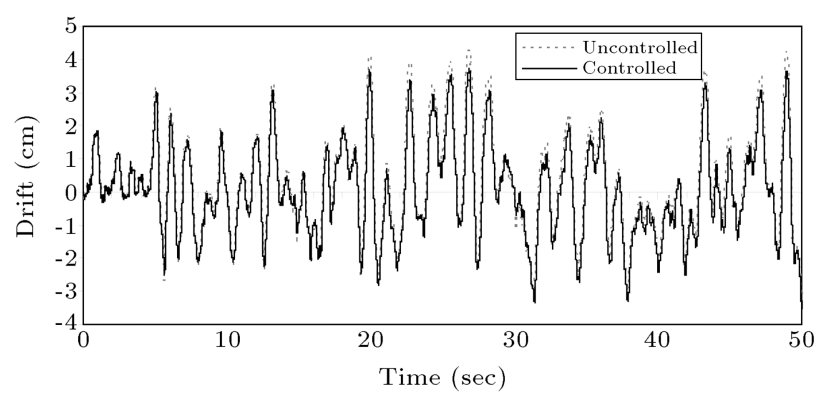

Figure 9. Maximum drifts of uncontrolled and controlled walls under scaled white noise excitation.

has been decided to design optimal TMDs based on minimization of the maximum drift.

Following the same procedure applied to Example 1 for $\mu=2.5 \%$ as a sample, the optimal TMD has been designed and the maximum drift of the controlled wall has been reported in Table 2 .

Figure 9 compares the maximum drift of the uncontrolled and controlled walls which shows about $13 \%$ reduction in the maximum drift for $\mu=2.5 \%$. As it has been concluded in Example 1, the reduction in the maximum response of the structure depends on the TMD mass ratio; hence, by increasing the mass ratio, it is possible to have more reduction in the maximum response.

According to the results, it can be said that the proposed method can also be used for designing optimal TMDs for multi-storey confined masonry walls. In applying TMDs on multi-storey confined masonry walls, the effect of TMD mass ratio and its location as well as design earthquake characteristics on TMD performance are some important issues which should be studied in future research. Also, to make the results applicable to real existing multi-storey confined masonry walls, it is needed to consider real properties for different storeys.

\section{Conclusions}

In this paper, the optimal design of Tuned Mass Dampers (TMDs) has been studied and its effectiveness in reducing the seismic response of confined masonry walls has been assessed. The optimal parameters of a 
TMD, including its stiffness and damping, have been determined by solving an optimization problem defined as minimization of the maximum drift, accumulated hysteretic energy or Root-Mean-Square (RMS) of drift using Genetic Algorithm (GA). To assess the effect of frequency content and Peak Ground Acceleration (PGA) of earthquake on TMD performance on confined masonry walls, different earthquakes scaled to different PGAs have been considered for designing optimal TMDs. To illustration, the method has been used to design TMD on one- and five-storey masonry walls which have been modeled by a tri-linear shear beam. Results show that the method has been effective in determining the optimal parameters of TMD regarding its simplicity and convergence behavior in solving the optimization problem using GA. It has also been found that application of TMD on confined masonry wall improves its seismic response and could prevent it from failure. Results of the numerical simulations have shown that Peak Ground Acceleration (PGA) and frequency content of earthquake affect the efficiency of TMD on masonry walls; hence, to design TMD in a particular area, the design earthquake of that area with a proper PGA should be considered as the external excitation. Parametric study on the effect of TMD mass ratio has shown that the reduction in maximum response of uncontrolled wall depends on the value of mass ratio. The results have shown that generally increasing the mass ratio leads to increasing the reduction in maximum response. Designing TMDs based on different criteria has shown that in order to achieve the most reduction in a specified response, it is necessary to consider minimization of that particular response as the performance index in the optimization problem. Preliminary study on application of TMD on multi-storey walls shows that the method can also be used for designing optimal TMDs on multi-storey masonry walls, while the effects of TMD mass ratio and its location as well as design earthquake characteristics should be considered as effective factors.

\section{References}

1. Moghaddam, H.A. and Dowling, P.J. "The state of the art in infilled frames", ESEE Research Report, No. 87-2, Civil Engineering Department, Imperial College, London, England (1987).

2. Dawe, J.L., Schriver, A.B. and Sofocleous, C. "Masonry infilled steel frames subjected to dynamic load", Canadian J. Civil Eng., 16, pp. 877-885 (1989).

3. Madan, A., Reinhorn, A.M., Mander, J.B. and Valles, R.E. "Modeling of masonry infill panels for structural analysis", J. Struct. Eng., ASCE, 123(10), pp. 12951302 (1997).

4. Tomazevic, M. and Klemenc, I. "Seismic behavior of confined masonry wall", Earthquake Eng. \& Struc. Dyn., 26, pp. 1059-1071 (1997).

5. Tomazevic, M. and Klemenc, I. "Verification of seismic resistance of confined masonry buildings", Earthquake Eng. \& Struc. Dyn., 26, pp. 1073-1088 (1997).

6. Moroni, M.O., Astroza, M. and Tavonatti, S. "Non linear models for shear failure in confined masonry walls", The Masonry Society (TMS) J., 12(2), pp. 7278 (1994).

7. Moroni, M.O., Astroza, M., Gomez, J. and Guzman, R. "Establishing $R_{w}$ and $C_{d}$ factors for confined masonry buildings", J. Struct. Eng., ASCE, 122(6), pp. 1208-1215 (1996).

8. Joghataie, A. and Mohebbi, M. "Vibration controller design for confined masonry walls by distributed genetic algorithms", J. Struct. Eng., ASCE, 134(2), pp. 300-309 (2008).

9. Soong, T. and Dargush, G.F., Passive Energy Dissipation Systems in Structural Engineering, Chichester, John Wiley \& Sons (1997).

10. Li, C. and Zhu, B. "Estimating double tuned mass dampers for structures underground acceleration using a novel optimum criterion", J. Sound Vib., 298(1-2), pp. 280-297 (2006).

11. Moon, K.S. "Vertically distributed multiple tuned mass dampers in tall buildings: Performance and preliminary design", Struct. Design Tall Spec. Build, 19, pp. 347-366 (2010).

12. Mohebbi, M., Shakeri, K., Ghanbarpour, Y. and Majzob, H. "Designing optimal multiple tuned mass dampers using genetic algorithms (GAs) for mitigating the seismic response of structures", J. Vib. Control, 19(4), pp. 605-625 (2013).

13. Mohebbi, M., Moradpoor, M. and Ghanbarpour, Y. "Improving the seismic behavior of nonlinear steel structures using optimal MTMDs", Int. J. Optimiz. Civil Eng., 4(1), pp. 137-150 (2014).

14. Xiang, P. and Nishitani, A. "Seismic vibration control of building structures with multiple tuned mass damper floors integrated", Earthquake Eng. \& Struc. Dyn., 43, pp. 909-925 (2014).

15. Den Hartog, J.P., Mechanical Vibrations, 4th Edition, McGraw-Hill, New York (1956).

16. Warburton, G.B. "Optimal absorber parameters for various combinations of response and excitation parameters", Earthquake Eng. \& Struc. Dyn., 8, pp. 197217 (1982).

17. Luft, R.W. "Optimal tuned mass dampers for buildings", J. Struct. Division, ASCE, 105(12), pp. 27662772 (1979).

18. Sadek, F., Mohraz, B., Taylor, A.W. and Chung, R.M. "A method of estimating the parameters of tuned mass dampers for seismic application", Earthquake Eng. \& Struc. Dyn., 26, pp. 617-635 (1997). 
19. Bourquin, F., Caruso, G., Peigney, M. and Siegert, D. "Magnetically tuned mass dampers for optimal vibration damping of large structures", Smart Mater. \& Struct., 23, 085009(2014).

20. Gutierrez Soto, M. and Adeli, H. "Optimum tuning parameters of tuned mass dampers for vibration control of irregular high rise building structures", J. Civil Eng. \& Management, 20, pp. 609-620 (2014).

21. Marian, L. and Giaralis, A. "Optimal design of a novel tuned mass-damper-inerter (TMDI) passive vibration control configuration for stochastically support-excited structural systems", Prob. Eng. Mech., 38, pp. 156-164 (2014). Doi:10.1016/j.probengmech.2014.03.007

22. Kaynia, N.M., Veneziano, D. and Biggs, J.M. "Seismic effectiveness of tuned mass dampers", J. Struct. Division, ASCE, 107(8), pp. 1465-1484 (1981).

23. Soto-Brito, R. and Ruiz, S.E. "Influence of ground motion intensity on the effectiveness of tuned mass dampers", Earthquake Eng. \& Struc. Dyn., 28, pp. 1255-1271 (1999).

24. Lukkunaprasit, P. and Wanitkorkul, A. "Inelastic buildings with tuned mass dampers under moderate ground motions from distant earthquakes", Earthquake Eng. \& Struc. Dyn., 30, pp. 537-551 (2001).

25. Johnson, J.G., Pantelides, C.P. and Reaveley, L.D. "Nonlinear rooftop tuned mass damper frame for the seismic retrofit of buildings", Earthquake Eng. \& Struc. Dyn., 44(2), pp. 299-316 (Feb. 2015). Doi: $10.1002 /$ eqe. 2473

26. Sun, C., Nagarajaiah, S. and Dick, A.J. "Experimental investigation of vibration attenuation using nonlinear tuned mass damper and pendulum tuned mass damper in parallel", Nonlinear Dyn., 78, pp. 2699-2715 (2014).

27. Mohebbi, M. and Joghataie, A. "Designing optimal tuned mass dampers for nonlinear frames by distributed genetic algorithms", Struct. Design Tall Spec. Build, 21, pp. 57-722 (2012).

28. Holland, J.H., Adaptation in Natural and Artificial Systems, Ann Arbor: The University of Michigan Press (1975).

29. Goldberg, D.E., Genetic Algorithms in Search, Optimization and Machine Learning, Addison -Wesley Publishing Co., Inc. Reading, Mass (1989).

30. Michalewicz, Z. Genetic Algorithms + Data Structures = Evolution Programs, New York, Springer Verlag (1996).

31. Jenkins, W.M. "A decimal-coded evolutionary algorithm for constrained optimization", Comp. and Struct., 80, pp. 471-480 (2002).

32. Arfiadi, Y. and Hadi, M.N.S. "Optimal direct (static) output feedback controller using real coded genetic algorithms", Comp. and Struct., 79, pp. 1625-1634 (2001).

33. Baker, J.E. "Reducing bias and inefficiency in the selection algorithm", Proceeding of 2nd International Conference on Genetic Algorithm (ICGA), July, Cambridge, MA, USA, 2, pp. 14-21 (1987).
34. Mühlenbein, H. and Schlierkamp-Voosen D. "Predictive models for the breeder genetic algorithm: I. Continuous parameter optimization", Evolut. Comput., 1(1), pp. 25-49 (1993).

35. Hung, S.L. and Adeli, H. "A parallel genetic/neural network learning algorithm for MIMD shared memory machines", IEEE Trans. Neural Netw., 5(6), pp. 900909 (1994).

36. Sarma, K.C. and Adeli, H. "Bi-level a Algorithms for optimization of large steel structures", Comput.-Aided Civ. Inf., 16(5), pp. 295-304 (2001).

37. Adeli, H. and Kumar, S. "Distributed genetic algorithms for structural optimization", J. Aerospace Eng., $A S C E$, 8(3), pp. 156-163 (1995).

38. Sarma, K. and Adeli, H. "Fuzzy genetic algorithm for optimization of steel structures", J. Struct. Eng., $A S C E, \mathbf{1 2 6}(5)$, pp. 596-604 (2000).

39. Jiang, X. and Adeli, H. "Neuro-genetic algorithm for nonlinear active control of high rise buildings", Int. J. Numer. Methods Eng., 75(8), pp. 770-786 (2008).

40. Adeli, H. and Hung, S.L., Machine Learning - Neural Networks, Genetic Algorithms, and Fuzzy Sets, John Wiley and Sons, New York (1995).

41. Adeli, H. and Sarma, K., Cost Optimization of Structures - Fuzzy Logic, Genetic Algorithms, and Parallel Computing, John Wiley and Sons, West Sussex, United Kingdom (2006).

42. Siddique, N. and Adeli, H., Computational Intelligence - Synergies of Fuzzy Logic, Neural Networks and Evolutionary Computing, Wiley, West Sussex, United Kingdom (2013).

43. Adeli, H. and Cheng, N.-T. "Augmented Lagrangian genetic algorithm for structural optimization", $J$. Aerospace Eng., ASCE, 7(1), pp. 104-118 (1994).

44. Kim, H. and Adeli, H. "Discrete cost optimization of composite floors using a floating point genetic algorithm", Eng. Optimiz., 33(4), pp. 485-501 (2001).

45. Sarma, K.C. and Adeli, H. "Life-cycle cost optimization of steel structures", Int. J. Numer. Meth. Eng., 55(12), pp. 1451-1462 (2002).

46. Adeli, H. and Kumar, S. "Concurrent structural optimization on a massively parallel supercomputer", $J$. Struct. Eng., ASCE., 121(11), pp. 1588-1597 (1995).

47. Adeli, H. and Cheng, N.-T. "Integrated genetic algorithm for optimization of space structures", $J$. Aerospace Eng., ASCE, 6(4), pp. 315-328 (1993).

48. Fuggini, C., Chatzi, E., Zangani, D. and Messervey, T.B. "Combining genetic algorithm with a meso-scale approach for system identification of a smart polymeric textile", Comput.-Aided Civ. Inf., 28(10), pp. 227-245 (2013).

49. Lin, D.Y. and Ku, Y.H. "Using genetic algorithms to optimize stopping patterns for passenger rail transportation", Comput.-Aided Civ. Inf., 29(4), pp. 264278 (2014). 
50. Zhu, W., Hu, H. and Huang, Z. "Calibrating rail transit assignment models with genetic algorithm and automated fare collection data", Comput-Aided Civ. Inf., 29(7), pp. 518. 530 (2014).

51. Joghataie, A. and Mohebbi, M. "Designing optimal controllers for nonlinear frames by considering the effect of response feedback", Sci. Iran., A, 18(6), pp. 117-1178 (2011).

52. Joghataie, A. and Mohebbi, M. "Optimal control of nonlinear frames by Newmark and distributed genetic algorithms", Struct. Design Tall Spec. Build, 21, pp. 77-95 (2012).

53. Mohebbi, M. and Bagherkhani, A. "Optimal design of magneto-rheological dampers", Int. J. Optimiz. Civil Eng., 4(3), pp. 361-380 (2014).

54. Hejazi, F., Toloue, I., Noorzaei, J. and Jaafar, M.S. "Optimization of earthquake energy dissipation system by genetic algorithm", Comput.-Aided Civ. Inf., 28(10), pp. 796-81 (2013).

55. Pinkaew, T., Lukkunaprasit, P. and Chatupote, P. "Seismic effectiveness of tuned mass dampers for damage reduction of structures", Engrg. Struct., 25, pp. 39-46 (2003).

\section{Biographies}

Mohtasham Mohebbi received his BSc, MSc, and PhD degree in 1997, 1999, and 2008, respectively, from Sharif University of Technology (SUT), Tehran, Iran. He currently works as an Associate Professor in Engineering Department of University of Mohaghegh Ardabili, Ardabil, Iran. He has participated in writing a number of papers published in refereed journals and conference proceedings in the structural control field. His current research interests are in the fields of structural control systems (passive, active, and semiactive systems) and optimization in civil engineering.

Abdolreza Joghataie received his $\mathrm{PhD}$ degree from the University of Illinois at Urbana-Champaign, Illinois, US, in 1994 and is now a faculty member of the Structural and Earthquake Engineering Groups in Civil Engineering Department of Sharif University of Technology, Tehran, Iran. His research is within the fields of structural optimization, intelligent computation, structural control, and concrete structures. 